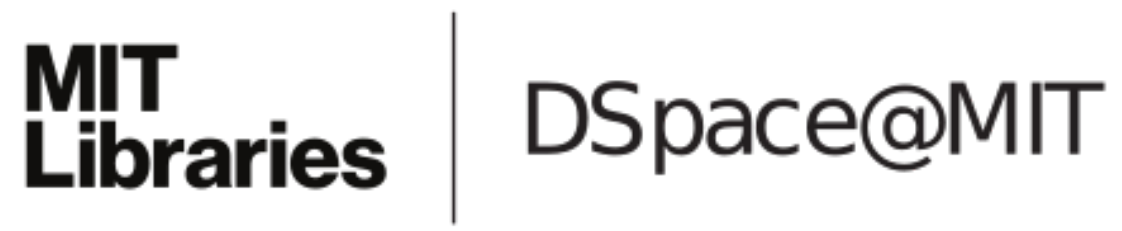

\author{
MIT Open Access Articles
}

\section{Influence of mass transfer and electrolyte composition on anodic oxygen evolution in molten oxides}

The MIT Faculty has made this article openly available. Please share how this access benefits you. Your story matters.

Citation: Caldwell, A. H., et al. "Influence of Mass Transfer and Electrolyte Composition on Anodic Oxygen Evolution in Molten Oxides." Electrochimica Acta, vol. 219, Nov. 2016, pp. 178-86.

As Published: https://doi.org/10.1016/j.electacta.2016.09.132

Publisher: Elsevier

Persistent URL: http://hdl.handle.net/1721.1/119244

Version: Author's final manuscript: final author's manuscript post peer review, without publisher's formatting or copy editing

Terms of use: Creative Commons Attribution-NonCommercial-NoDerivs License 
Abstract on anodic oxygen evolution in molten oxides

\author{
A. H. Caldwell, E. Lai, A. J. Gmitter ${ }^{1}$ and A. Allanore (ISE member) \\ Department of Materials Science and Engineering, Massachusetts Institute of Technology, \\ 77 Massachusetts Avenue, Cambridge, \\ MA 02139, USA \\ allanore@mit.edu
}

13 oxides at $1570{ }^{\circ} \mathrm{C}$ was experimentally investigated using both direct and alternating current methods.

14 Static and rotating electrode results show the presence of anodic reactions of iridium in addition to 15 oxygen evolution. In the context of electrochemical engineering of molten oxide electrolysis, the 16 results confirm prior theoretical calculations (Allanore, Electrochimica Acta, 2013) that suggested an 17 essential role of convection and electrolyte composition on the ability to sustain oxygen evolution at 18 high current densities. In addition, the reported results show that electrochemical measurements in 19 molten oxides coupled with mass-transfer models are complementary characterization tools for 20 oxygen chemistry.

23 Keywords: molten oxides, oxygen evolution, rotating electrode, ac voltammetry, iridium, silicates

\footnotetext{
${ }^{1}$ present address Merck \& Co., Inc. (Merck Sharp \& Dobme outside the US and Canada) Center for Materials Science \& Engineering, WP75B-210, 770 Sumneytown Pike West Point, PA 19486
} 


\section{Introduction}

Molten oxides are one possible electrolyte for the direct decomposition of metal oxide to

3 produce metal and oxygen in an electrochemical process. Assuming the dissociation of the feed

4 oxide $\mathrm{MO}$ into its constituent ions in the molten oxide electrolyte, the target cathode and anode

5 reactions are commonly written:

$6 \quad \mathrm{M}^{2+}+2 \mathrm{e}^{-} \rightarrow \mathrm{M}_{(1)}$

(Reaction 1)

$7 \quad \mathrm{O}^{2-} \rightarrow 2 \mathrm{e}^{-}+\frac{1}{2} \mathrm{O}_{2(\mathrm{~g})}$

(Reaction 2)

8 As discussed in a recent review [1], numerous examples of successful production of metal by

9 electrolysis in molten oxides have been reported (e.g. for Fe, Mn, Si) but knowledge of the

10 underlying electrochemistry is limited. In particular, electrochemical insights into the anodic reaction

11 (Reaction 2) are lacking. According to prior electrochemical investigations, reviewed in references [1]

12 and [2], the free oxide ion $\left(\mathrm{O}^{2-}\right)$ is the reacting species at the anode. Prior work [2] proposed

13 integration of available literature data and knowledge of the physical-chemistry of oxygen in molten

14 oxides to evaluate the possible mass-transfer limitations of the oxygen evolution reaction

15 (Reaction 2). In that prior chemical engineering approach, the role of convection induced by gas

16 evolution was put forth as an important phenomenon that enhances the limiting current for oxygen

17 evolution in molten oxides.

18 The present work aims to provide experimental evidence of the role of mass-transfer on

19 Reaction 2. Electrochemical measurements of the anodic evolution of oxygen on iridium as both a

20 static and a rotating electrode, using direct (dc) and alternating (ac) current methods, are reported

21 herein. In addition, electrochemical measurements in different electrolytes are presented,

22 demonstrating the utility of electrochemistry for probing oxygen chemistry in-situ. Lastly, the

23 essential role of the supporting electrolyte design for the evolution of oxygen by electrolysis in

24 molten oxides is highlighted.

\section{Experimental}

\section{Materials}

28 Reagent grade (purity min. $98 \%$ ) silica, alumina, magnesia, and calcia powders were 29 individually weighed and manually mixed by shaking in a polyethylene bottle prior to being packed

30 directly in an alumina crucible (purity min. $98 \%$ ). Table 1 provides a list of the compositions 
1 investigated and their calculated optical basicity, along with their density and dynamic viscosity 2 reported in reference [3]. Only one electrolyte contained magnetite (purity min $98 \%$ ), added at 3 around 2 wt $\%$.

\begin{tabular}{|l|l|l|l|l|l|l|l|l|}
\hline & \multicolumn{3}{|l}{$\begin{array}{l}\text { Composition } \\
\text { ID } \%\end{array}$} & & $\begin{array}{l}\text { Optical } \\
\text { basicity }\end{array}$ & $\begin{array}{l}\text { Density } \\
\mathrm{kg} \mathrm{m}^{-3}\end{array}$ & $\begin{array}{l}\text { Kinematic viscosity } \\
\mathrm{m}^{2} \mathrm{~s}^{-1}\end{array}$ \\
\hline & $\mathrm{CaO}$ & $\mathrm{MgO}$ & $\mathrm{Al}_{2} \mathrm{O}_{3}$ & $\mathrm{SiO}_{2}$ & $\mathrm{Fe}_{3} \mathrm{O}_{4}$ & & & \\
\hline $\mathrm{SA} 1$ & 27 & 8 & 23 & 42 & - & 0.62 & 2720 & $3.62 \times 10^{-4}$ \\
\hline \hline SB2 & 31 & 8 & 17 & 44 & - & 0.63 & 2705 & $2.75 \times 10^{-4}$ \\
\hline SB2F & 30.3 & 7.8 & 16.6 & 43.1 & 1.9 & - & - & - \\
\hline \hline SB3 & 37 & 10 & 19 & 34 & - & 0.66 & 2749 & $1.47 \times 10^{-4}$ \\
\hline SB4 & 50 & 6 & 0 & 44 & - & 0.68 & 2651 & $7.92 \times 10^{-4}$ \\
\hline
\end{tabular}

5 Table 1. Composition and physical-chemical properties of the electrolytes.

Iridium (> $99.9 \%$, Furuya Metals, Japan) was used as an anode in the form of a wire 7 (0.5 mm diameter) or a rod ( $3 \mathrm{~mm}$ diameter). Molybdenum (Ed Fagan, USA) was used as a quasi8 reference (rod of $3 \mathrm{~mm}$ diameter) and counter electrode (rod of $3 \mathrm{~mm}$ diameter or foil of $0.5 \mathrm{~mm}$ 9 thickness shaped into a cylinder occupying circumference of the crucible section), welded to 10 molybdenum rods $(3 \mathrm{~mm})$ that served as current leads. All electrode leads were protected using 11 alumina tubes (6.4 $\mathrm{mm}$ diameter, CoorsTek), and alumina cement was used to cover the welds

12 exposed to high temperature (Alumina Cement Type AL-CEM, Zircar). Viton ${ }^{\mathrm{TM}}$ O-rings and epoxy 13 were used to seal the tubes and the furnace cap from the ambient environment. All experiments 14 were conducted in argon atmosphere with a flow rate of $150 \mathrm{~mL} \mathrm{~min}^{-1}$ (Airgas, < $10 \mathrm{ppm}_{2}$ ), 15 leading to an oxygen partial pressure in the tube furnace atmosphere of $50 \mathrm{ppm}$ measured at the 16 outlet.

\section{High Temperature Assembly}

18 The alumina crucible $\left(600 \mathrm{~cm}^{3}\right.$ capacity, internal diameter of $\left.6.5 \mathrm{~cm}\right)$ containing the 19 electrolyte (around $150 \mathrm{~cm}^{3}$ or $4 \mathrm{~cm}$ height when molten) was placed in a secondary crucible, itself 20 placed in a closed one end alumina tube equipped with a water-cooled cap with Ultra-Torr ${ }^{\mathrm{TM}}$ 21 vacuum feed-through fittings for the movement and insertion of the electrode leads. The whole 22 assembly was placed in a furnace equipped with lanthanum chromite heating elements (model: PVT 23 18/100/350, Carbolite, UK). The furnace temperature controller was set at a temperature 
1 of $1630{ }^{\circ} \mathrm{C}$, with a ramping rate of $84^{\circ} \mathrm{C} \mathrm{h}^{-1}$. Independent measurement of the temperature directly

2 above the electrolyte with a B-type thermocouple confirmed a $60{ }^{\circ} \mathrm{C}$ difference with the furnace set-

3 point temperature. The reported temperature in this work is therefore $1570{ }^{\circ} \mathrm{C}$.

4 Electrode Configuration

5 The electrode configuration for the static anode measurements consisted of three vertical

6 electrodes in a triangular configuration as viewed from above the crucible. The working electrode

7 was an iridium wire with an exposed surface area ranging from $0.017 \mathrm{~cm}^{2}$ to $0.10 \mathrm{~cm}^{2}$ depending on

8 the immersion depth. The two other electrodes, counter and reference, were made of $3 \mathrm{~mm}$

9 diameter molybdenum rod and immersed at least $1 \mathrm{~cm}$ deeper than the tip of the iridium working

10 electrode.

11 The rotating iridium electrode (see Appendix 1 for a schematic) consisted of a $3 \mathrm{~mm}$

12 diameter iridium rod inserted in a molybdenum rotating shaft (1 cm outer diameter OD). The shaft

13 was guided by a molybdenum tube $(2.54 \mathrm{~cm} \mathrm{OD})$ and a stabilization ring. The molybdenum tube

14 and the shaft were able to jointly slide along the length of the tube furnace through the cap via a

15 vacuum fitting $(2.54 \mathrm{~cm}$ ID). The seal between the rotating shaft and the tube was maintained

16 outside of the furnace by a custom-made aluminium casing and compression cap, equipped with a

17 conical spring seal (Vulcan Type 8). Rotation of the shaft was achieved through an overhead stirrer

18 (Heidolph 2102 RZR) equipped with a rubber coupling. Electrical connection was made by

19 connecting a wire between the shaft and an aluminium tube extending through and above the stirrer

20 chuck. The aluminium extension tube was then connected to a rotary electrical contact (Mercotac,

21 Model 105). The counter electrode for the rotating electrode experiments was a molybdenum

22 cylinder $0.5 \mathrm{~mm}$ thick that occupied the internal circumference of the alumina crucible.

23 For all measurements, after a holding time at the target temperature of half an hour to one

24 hour, the reference and counter electrodes were successively lowered into the molten electrolyte.

25 The melt position was detected through a sharp decrease in the resistance between the electrodes as

26 measured with an ohmmeter. With the two electrodes in position, the working electrode was

27 lowered last and its contact with the melt determined by the ohmmeter. The working electrode was

28 then immersed between $2 \mathrm{~mm}$ and $5 \mathrm{~mm}$ into the electrolyte.

29 Electrochemical Measurements

30 Electrochemical signals from the static electrode were recorded with a potentiostat (model 31 1287, Solartron) and a frequency response analyzer (FRA) (model 1260, Solartron). Measurements 32 from the rotating electrode were recorded using another potentiostat/FRA (PGSTAT302N, 
1 AutoLab). The open-circuit potential (OCP) was recorded after immersion of the electrodes, 2 typically followed by electrochemical impedance spectroscopy (EIS) at the OCP. This last 3 measurement was used post-experiment to evaluate the uncompensated resistance, obtained as the

4 real component of the impedance when the imaginary component is zero. The potentials reported in 5 this work are corrected by the ohmic drop arising from the uncompensated resistance and 6 referenced to the molybdenum reference electrode potential. The molybdenum electrode is assumed 7 to be in equilibrium with $\mathrm{MoO}_{2}(\mathrm{~s})^{2}$. The reference potential is then assumed to be fixed by the 8 equilibrium Reaction 3, for which the standard decomposition voltage at $1570{ }^{\circ} \mathrm{C}$ is $9 \Delta \mathrm{E}_{\text {decomp. }}^{\circ}=-0.688 \mathrm{~V}$.

$10 \mathrm{Mo}+\mathrm{O}_{2(\mathrm{~g})} \Leftrightarrow \mathrm{MoO}_{2(\mathrm{~s})}$

(Reaction 3)

11 Potential scan measurements, both in direct current (dc) and alternating current (ac), were 12 then recorded. Constant potential measurements at different working electrode heights were 13 conducted to extrapolate the active surface area, following the method presented in reference [4]. 14 The rotating electrode performance was validated in the same configuration as that at $1570{ }^{\circ} \mathrm{C}$, using 15 the hexacyanoferrate(III/II) oxidation-reduction reaction in $1 \mathrm{M} \mathrm{KOH}$ at room temperature, 16 substituting the molybdenum electrodes with nickel. The measurements made in these conditions 17 confirmed a Levich-type relation between the limiting current and the rotation rate, with a diffusivity 18 of hexacyanoferrate(III) of $5.5 \times 10^{-10} \mathrm{~m}^{2} \mathrm{~s}^{-1}$ in agreement with prior reports [5].

\section{Results}

Static Electrode

DC and ac static electrode measurements were conducted in the various electrolytes 22 presented in Table 1. A cyclic voltammogram recorded for the first two sweeps between the OCP 23 and $2.5 \mathrm{~V}$ at $20 \mathrm{mV} \mathrm{s}^{-1}$ in electrolyte SB4 is shown in Figure 1a. [FIGURE 1 HERE] As a 24 representative example, the measurements made in electrolyte SB4 are presented to illustrate the key 25 features of electrochemical measurements in molten oxides. As shown in the inset, an anodic current 26 slightly increasing with the potential is observed upon departure from the OCP during the positive27 going potential scan. The current remains relatively small (maximum of $5 \times 10^{-3} \mathrm{~A} \mathrm{~cm}^{-2}$, range 1) until 28 around $0.9 \mathrm{~V}$ at which point it exhibits a sharp increase and a change of slope. The current measured 29 during the negative-going potential scan in this potential region exhibits a completely different

\footnotetext{
${ }^{2}$ The choice of $\mathrm{MoO}_{2}(\mathrm{~s})$ as the solid oxide species in equilibrium with Mo is informed from the Mo- $\mathrm{O}_{2}$ phase diagram which indicates this solid oxide as the stable species at $1600^{\circ} \mathrm{C}$ in a reducing atmosphere.
} 
1 behavior, being mostly cathodic, and exhibiting a peak (point $\mathrm{C}$ ) at around $0.75 \mathrm{~V}$. Both the anodic

2 and cathodic features in this potential region are, within the uncertainty of our measurements, 3 reproducible from cycle to cycle.

4 At potentials more positive than range 1 in Figure 1a, the current is large and two additional 5 potential ranges can be distinguished. Range 2 has been defined from $0.9 \mathrm{~V}$ to $1.1 \mathrm{~V}$, a range of 6 potentials for which the anodic current signals for both the positive-going potential scan and the 7 negative-going potential scan overlap. Range 3 has been defined for potentials larger than $1.1 \mathrm{~V}$, a 8 range of potentials for which the recorded current is noisy and exhibits hysteresis between the 9 positive-going and negative-going potential scans. None of the characteristic currents exhibited a 10 clear functional dependence on the scan rate. However, changing the anodic (positive) and cathodic 11 (negative) switching potentials revealed that the anodic current in the positive-going potential scan in 12 range 2 was responsible for the cathodic peak $\mathrm{C}$ observed during the negative-going potential scan. 13 The current at the cathodic peak $\mathrm{C}$ proved independent of the duration of the scan in range 3.

14 DC voltammograms recorded in electrolytes of decreasing basicity are presented in 15 Figure 1b. With the exception of electrolyte SA1, the most acidic electrolyte, decreasing the basicity 16 leads to a larger current in range 1. The current-potential data in range 2, despite shifting to potentials 17 closer to the OCP with decreasing optical basicity, exhibits both a decreasing slope and hysteresis as 18 the basicity is decreased. In range 3, the current and its variation with potential (slope) is 19 systematically smaller with decreasing basicity.

20 The impedance spectrum recorded at the OCP is presented in Figure 2. [FIGURE 2 HERE]

21 At frequencies larger than $20 \mathrm{kHz}$, the impedance spectrum is dominated by an inductance (positive 22 imaginary component) that is characteristic of high-temperature measurements [6]. This is attributed 23 to the long electrode leads that connect the end of the potentiostat cables to the active electrode 24 area, located in the hot zone of the furnace. An almost constant real component is evident in the 25 impedance spectrum between $20 \mathrm{kHz}$ and $2 \mathrm{kHz}$ and is attributed to the solution resistance between 26 the working electrode and the reference. At frequencies less than $100 \mathrm{~Hz}$, the impedance phase angle 27 is $45^{\circ}$, a feature indicative of an electrochemical reaction controlled by diffusion. The impedance 28 data is unreliable for frequencies less than $0.5 \mathrm{~Hz}$. This impedance spectrum is remarkably similar to 29 that reported for gold electrodes in molten lithium carbonate [7]. Adopting the equivalent circuit 30 proposed by this reference leads to the parameters presented in Appendix 2, in which the numerical 31 results are reported. A systematic evaluation of impedance spectroscopy at dc potentials different 
1 from the OCP, including at different perturbation amplitudes, unfortunately proved unsuccessful at 2 providing meaningful and reproducible results.

3 AC voltammetry using the Mott-Schottky (MS) technique was used as an alternative to linear

4 dc voltammetry. For clarity, it should be noted that the term "Mott-Schottky" as used here and 5 throughout the manuscript refers to the single-frequency, linear potential sweep impedance 6 technique that is a standard feature of modern potentiostats and goes by the same name; it does not 7 refer to the analysis often employed for semiconductor electrodes to calculate charge carrier 8 densities from capacitance measurements. Figure 3 is a Nyquist representation of the Mott-Schottky 9 measurements for electrolyte SB4. [FIGURE 3 HERE] The impedance data near the open circuit 10 potential $(0.551 \mathrm{~V})$ adopt a characteristic arc-shape, matching the curve recorded by EIS at the OCP 11 (Figure 1). As the potential becomes more positive and extends through range 1 (up to $0.911 \mathrm{~V}$ ), the 12 iso-potential impedance curves bend, contracting towards smaller imaginary and real values. This 13 evolution of the impedance spectra reflects changes in the mass transport characteristics of the 14 electrochemical reactions at the working electrode. At dc potentials greater than $0.951 \mathrm{~V}$, the iso15 potential impedance curves shifts toward larger values of the real impedance, which suggests an 16 increase in the uncompensated resistance. The impedance measurements do not exhibit a systematic 17 and discernable trend with frequency for potentials larger than around $1.050 \mathrm{~V}$ (i.e., at the transition 18 from range 2 to range 3), though the trend of increasing uncompensated resistance described above 19 remains observable until $1.371 \mathrm{~V}$, at which point the uncompensated resistance is twice that at the OCP. [FIGURE 4 HERE]

To evaluate the faradaic ac modulus, the external inductance $\left(Z_{\mathrm{L}}=5 \times 10^{-7} \mathrm{H}\right)$ and 22 uncompensated resistance $\left(Z_{R}=Z_{R e}\left(Z_{I m}=0\right)\right)$ contributions were corrected for [9], following 23 Equation 1.

$24 \quad \mathrm{I}_{\mathrm{ac}}^{\mathrm{far}}=\frac{\Delta \mathrm{E}}{\sqrt{\left(\mathrm{Z}_{\mathrm{Re}}-\mathrm{Z}_{\mathrm{R}}\right)^{2}+\left(\mathrm{Z}_{\mathrm{Im}}-\mathrm{Z}_{\mathrm{L}}\right)^{2}}}$ (Equation 1) The corresponding plot of the faradaic ac modulus as a function of the de potential is 26 presented in Figure 5a for a dc potential up to $0.74 \mathrm{~V}$ (range 1). A background current is observed 27 near the OCP, particularly pronounced above $300 \mathrm{~Hz}$. [FIGURE 5 HERE]

28 An ac amplitude waveform centered at $0.47 \mathrm{~V}$ (label A1) is observed, the magnitude of 29 which increases with increasing frequency. The potential of the ac amplitude peak shifts toward 30 positive values at frequencies larger than $300 \mathrm{~Hz}$. The remainder of the potential sweep exhibits a 31 second faradaic event near $1.0 \mathrm{~V}$, as presented in Figure $5 \mathrm{~b}$ on a scale ten times larger than in 
1 Figure 5a. Figure 5b shows only a selected number of frequencies for clarity in the most anodic

2 portion of the voltammogram. The rising portion of the ac amplitude for this second faradaic event 3 begins at $0.68 \mathrm{~V}$ and has a monotonic variation in range 1 (until around $1.010 \mathrm{~V}$ ) where it reaches

4 values seven to ten times larger than the one observed for the event $A 1$. After this potential, in

5 range 2, the current abruptly and systematically drops in the region of $1.010-1.050 \mathrm{~V}$. Beyond this 6 potential (range 3) the current adopts values similar to or higher to that at $1.010 \mathrm{~V}$, but is 7 exceptionally noisy, in agreement with the raw impedance data presented in the Nyquist plot of 8 Figure 3 and the dc data in Figure 2a. The dotted line presented in Figure 5b shows the average ac 9 amplitude calculated for potentials above $1.050 \mathrm{~V}$. The values of the peak current for the faradaic 10 events $A 1$ and $A 2$ are shown in Figure 6. [FIGURE 6 HERE] The peak currents for both $A 1$ and $11 A 2$ are proportional to the square-root of the frequency for frequencies lower than $5 \mathrm{kHz}$. This 12 dependence is characteristic of a faradaic reaction controlled by mass transfer.

13 Rotating Electrode

14 DC voltammograms recorded on a rotating cylinder iridium electrode in electrolyte SB2F for 15 various rotation rates are presented in Figure 7. [FIGURE 7 HERE] A non-zero current is observed 16 for potentials greater than $0.2 \mathrm{~V}$, leading to a plateau as it enters range 1 . This current is much larger 17 than that observed in the absence of iron (see Figure 2b, curve SB3), suggesting the current is due to 18 the oxidation of iron ions. Other features of the voltammogram at potentials more positive than $190.5 \mathrm{~V}$ but less than $1.1 \mathrm{~V}$ (range 1 and range 2) are very similar to those evident in Figure 2b. A 20 variation of the current with the rotation rate is noticed, though it is not monotonic in ranges 1 and 2. 21 It was observed that rotation of the electrode always increased the current with respect to a static 22 measurement, but this increase was not systematically proportional to the rotation speed. In 23 contrast, the current in range 3 (potential greater than $1.1 \mathrm{~V}$ ) is increasing monotonically with the 24 rotation rate. Taking the maximum current value recorded at a potential of $1.499 \mathrm{~V}$, a Koutecký25 Levich plot can be constructed and fit with a linear regression, though its interpretation is rendered 26 difficult by the absence of a well-defined limiting current plateau. The current in the negative-going 27 potential scan shows a remarkably consistent crossing point with the current of the positive-going 28 potential scan, at $0.8 \mathrm{~V}$ and almost zero current. The current for the cathodic signal $\mathrm{C}$ decreases with 29 increasing rotation rate, indicative of the surface-confined nature of the anodic species formed in the 30 potential range 2. 


\section{Discussion}

The static electrode results presented herein match unpublished data recorded independently

3 several years ago [4], suggesting the reproducibility of the measurements. Despite the lack of a

4 detailed description of the chemical entities constituting the specific molten oxide compositions

5 investigated in this work, the consistency of the electrochemical signals recorded across

6 configurations and techniques provides important insights.

$7 \quad$ In range 3 (see Figure 2) the dc and ac currents are much larger than for any of the other 8 potential ranges, and the uncompensated resistance increases even further than for range 2. The 9 anodic evolution of oxygen gas (Reaction 2) is proposed as the corresponding faradaic reaction.

10 Static electrode de voltammetry and Mott-Schottky measurements as well as the rotating electrode

11 results all support the conclusion that mass-transfer plays an essential role for this reaction. The 12 influence of mass-transfer on electrochemical oxygen evolution is a point of interest for molten 13 oxides (see [2]) and is in principle amenable to analysis by quantifying the limiting current density.

14 Such an analysis was done with the voltammetry data on a static electrode recorded in 15 electrolytes of different compositions, as shown in Figure 2b, assuming that the current density 16 measured at a given anodic dc potential is indeed transport-limited. This current density, here 17 evaluated at $2 \mathrm{~V}$, can provide an estimate of the concentration of free oxygen anions assuming 18 particular transport models. Reference [2] presents several models that could represent 19 hydrodynamic conditions in the absence of forced convection, suggesting a boundary layer thickness 20 of a few microns to several tens of microns, with a very minor variation across electrolyte 21 compositions. To facilitate analysis, and in the absence of a complete fluid mechanics model of 22 transport in molten oxides in the relevant electrode configurations, a simplified Nernst model is first 23 used in the present work. A boundary layer of $40 \mu \mathrm{m}$ is assumed along with a free oxygen anion 24 diffusivity of $10^{-10} \mathrm{~m}^{2} \mathrm{~s}^{-1}$. The corresponding estimated concentration of free oxygen is presented in 25 Figure 9, along with values calculated from X-ray photoelectron spectroscopy data and Raman 26 spectroscopy data reported by Park ([8],[9]), as a function of the optical basicity. Our 27 electrochemical results suggest a concentration of reactive oxygen species with the same order of 28 magnitude as what has been reported with the above spectroscopic techniques. In particular, the 29 trend with basicity, which is remarkably close to the one calculated from Raman spectroscopy data, 30 confirms the results from the free oxygen transport calculations reported in reference [2]. As a 31 consequence, the change in the dynamic viscosity of molten oxides with optical basicity affects, if 32 not dictates, the current density for oxygen gas production. This is very uncommon for supporting 
1 electrolytes in metal extraction, which typically have highly mobile or available anionic species. This

2 is however not entirely surprising for molten oxides containing network modifiers like calcium oxide 3 or magnesium oxide, which are considered to provide the alkaline-earth cations responsible for the 4 transport properties in molten oxides, including enhanced ionic conduction (see reference [1] for a 5 review).

6 The Nernst boundary layer used in this work to justify the experimental current densities 7 however cannot correspond solely to natural convection. Calculations for the latter transport 8 phenomenon, assuming a density difference of $20 \%$ at the electrode (see [2]), indeed predict a 9 current density that is half that reported in this work. Bubble-enhanced convection as presented in 10 [2] to take into account the role of oxygen bubble evolution remains a pertinent transport model in 11 light of the present experimental results. Application of this model - named the Levich model in 12 reference [2] - to match the experimental current density suggests oxygen bubble diameters in the 13 range $50 \mu \mathrm{m}$ to $200 \mu \mathrm{m}$.

14 The plots in Fig. 2 show the presence of two electrochemical reactions at potentials less 15 positive than oxygen evolution. These reactions are responsible for the ac amplitude waveforms 16 corresponding to peaks $A 1$ and $A 2$. While the focus of this study is oxygen evolution, a description 17 of the anodic behavior of iridium in molten oxides is also of some interest, and therefore part of this 18 discussion is set aside to interpret these ancillary electrochemical signals.

19 The reaction corresponding to peak $A 2$ is observed by voltammetry in range 2 (see Figure 2), 20 leading to an increase in the uncompensated resistance (see Figure 4), at a potential of around $210.95 \mathrm{~V}$. The faradaic ac amplitude data as well as data from the rotating electrode measurements 22 associated with this reaction in range 2 are indicative of a mass-transfer-controlled event. The results 23 of the static dc cyclic voltammetry measurements (Figure 2) indicate that the anodic current in the 24 positive-going potential scan produces an oxidized species that is responsible for the cathodic peak 25 current $C$ observed during the negative-going potential scan (point $C$ in Figure 2). The cyclic 26 voltammograms recorded from the rotating electrode (Figure 7) show that the magnitude of the 27 current at point $\mathrm{C}$ decreases with increasing rotation rate, suggesting that the reacting species is a 28 product of the prior positive-going potential scan that is localized near the electrode surface. This 29 body of experimental dc and ac data hints at the likelihood of an electrochemical reaction in range 2, 30 immediately prior to the onset of oxygen gas evolution. Considering the potential range for this 31 reaction, as well as prior results showing the presence of bubble-like features rich in iridium near the 32 electrode surface (see Figure 8 in reference [10] and the thermodynamic discussions therein), it is 
1 proposed that this reaction involves the formation of a gaseous species that contains iridium in an

2 oxidized form. The standard decomposition potential of $\mathrm{IrO}_{2}(\mathrm{~g})$ is indeed $\Delta \mathrm{E}_{\text {decomp. }}=+0.460 \mathrm{~V}$ at

$31570{ }^{\circ} \mathrm{C}$, which is $1.15 \mathrm{~V}$ more anodic than the molybdenum reference potential discussed in the

4 experimental section. The potential difference of $1.15 \mathrm{~V}$ is in reasonable agreement with the

5 electrochemical results, for which range 2 is defined to be $0.9 \mathrm{~V}$ to $1.1 \mathrm{~V}$. The gaseous nature of the

6 anodic product $\mathrm{IrO}_{2}$ may account for the increase in the uncompensated resistance and the sharp

7 drop in ac current observed at $1.040 \mathrm{~V}$ in the Mott-Schottky measurements (Figure 5b).

8 The existence of the ac amplitude peak $A 1$ at $0.47 \mathrm{~V}$ in the plot in Figure 2 suggests that a

9 faradaic reaction is occurring at potentials near OCP, though the reaction itself is not known. This

10 faradaic reaction may be establishing the iridium reference potential and hence the OCP of the

11 electrochemical cell. The linear relation between the $A 1$ ac amplitude peak and the square root of

12 the perturbation frequency is indicative of fast electron transfer kinetics and hence of a total

13 dependence on mass transfer of the corresponding reaction (see Figure 6). Furthermore, the

14 impedance spectrum at the OCP (Figure 1) is remarkably well-matched with impedance spectra

15 reported in other molten salt/oxide supporting electrolytes, confirming a key role of diffusion and

16 mass transfer on the equilibrium of the iridium electrode in molten oxides. The faradaic reaction at

$17 A 1$, then, may be the result of this equilibrium reaction being driven anodically at potentials more

18 positive than $0.65 \mathrm{~V}$ vs $\mathrm{E}_{\text {ref }}$ (range 1). Considering the chemical species present in the electrolyte and

19 at the iridium electrode, the oxidation of the iridium working electrode to iridium ions ( $+\mathrm{IV})$ is a

20 possible reaction, though further analysis (e.g., employing platinum electrodes) is required to

21 definitively exclude other possibilities such as the presence of metallic impurities in the melt that

22 may be responsible for the faradaic reaction at $A 1$.

\section{Conclusions}

24 The experimental results of $\mathrm{dc}$ and ac electrochemical methods, with static and dynamic 25 electrodes, confirm the key role of mass transport on anodic reactions on iridium in molten oxides.

26 Regarding the oxygen evolution reaction specifically, the results corroborate prior theoretical

27 calculations established from available physico-chemical data from molten oxide chemistries. From

28 an electrochemical engineering standpoint, it is concluded that the marked changes in the physical-

29 chemical properties of molten oxides with composition will affect the current density for the

30 electrolytic production of oxygen gas. Recognizing such feature is foreseen as essential for the

31 optimization of the electrolyte composition in order to design metal electrolysis processes based on

32 molten oxides. 
Acknowledgments The support for this research comes from the American Iron and Steel

2 Institute and the Office of Naval Research (contract \# N00014-11-1-0657).

4 References

5 [1] A. Allanore, Features and challenges of molten oxide electrolytes for metal extraction,

[2] A. Allanore, Electrochemical engineering of anodic oxygen evolution in molten oxides, Electrochim. Acta. 110 (2013) 587-592. doi:10.1016/j.electacta.2013.04.095.

[3] M. Allibert, H. Gaye, J. Geiseler, D. Janke, B.J. Keene, D. Kirner, M. Kowalski, J. Lehmann,

[4] A.J. Gmitter, The Influence of Inert Anode Material and Electrolyte Composition on the Electrochemical Production of Oxygen from Molten Oxides, Master Thesis available at dspace.com, Massachusetts Institute of Technology, 2008.

[5] H. Hiraoka, S; Yamada, I.; Ikeno, H.; Asano, H.; Nomura, S; Okada, T.; Nakamura, measurement of diffusivities of ferri- cyanide and ferrocyanide ions in dilute solution with KOH supportinge electrolyte, J. Chem. Eng. Japan. 14 (1981) 345-351.

[6] A. Kisza, The origin of inductance in high energy electrode reactions, Pol. J. Chem. 70 (1996) 922-938.

[7] B.B. Dave $\square$, R.E. White, S. Srinivasan, A.J. Appleby, Impedance analysis for oxygen reduction in a lithium carbonate melt: effects of partial pressure of carbon dioxide and temperature, J. Electrochem. Soc. 140 (1993) 2139-45. doi:10.1149/1.2086036.

[8] J.-H. Park, P.C.-H. Rhee, Ionic properties of oxygen in slag, J. Non. Cryst. Solids. 282 (2001) 7-14. doi:10.1016/S0022-3093(01)00323-4.

[9] J.H. Park, Structure-property relationship of $\mathrm{CaO}-\mathrm{MgO}-\mathrm{SiO}_{2}$ slag: Quantitative analysis of raman spectra, Metall. Mater. Trans. B. 44 (2013) 938-947. doi:10.1007/s11663-013-9825-9.

[10] H. Kim, J. Paramore, A. Allanore, D.R. Sadoway, Electrolysis of molten iron oxide with an iridium anode: the role of electrolyte basicity, J. Electrochem. Soc. 158 (2011) E101. doi:10.1149/1.3623446. 
2 Appendix 1. Schematic of the rotating iridium electrode assembly (half-view) 3

4
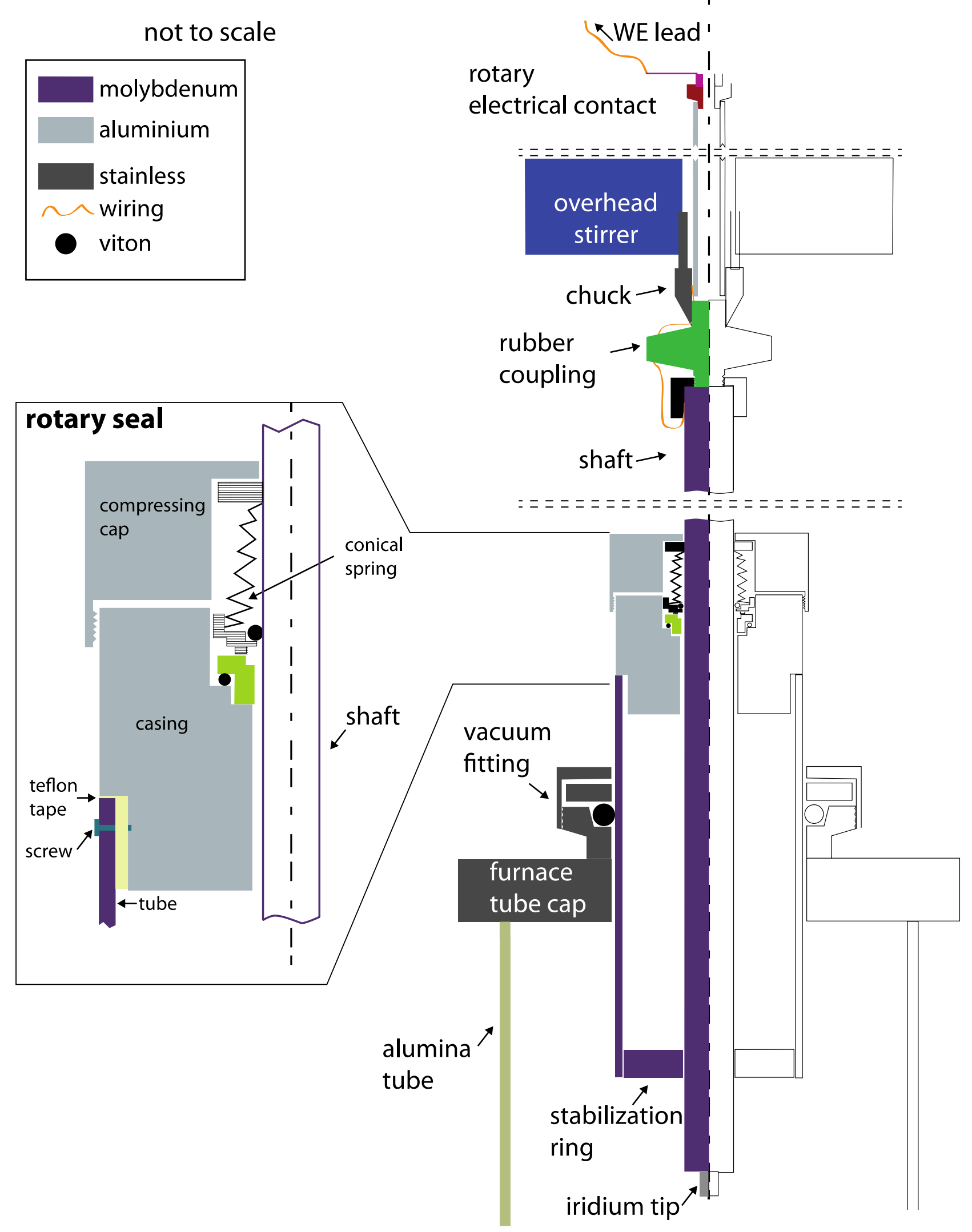


\section{Appendix 2. fitted impedance circuit parameters}

The equivalent circuit is presented in inset Figure 1, where the Warburg impedance assumes

4 a finite-length diffusion with reflective boundary. The charge transfer resistance proved extremely

5 difficult to evaluate, as expected for high temperature kinetics and the fact that the measurement is

6 conducted at OCP. It has therefore been fixed at an arbitrary value prior to fitting the other

7 parameters of the model.

8 Table A2 below presents the parameters for the fitting shown in Figure 2, where the 9 electrode surface area is estimated at $0.017 \mathrm{~cm}^{2}$.

10

11 Table A2. Results of the fitting of the impedance data to the circuit presented in inset in Fig. 2

\begin{tabular}{|c|c|c|c|c|c|c|c|}
\hline $\begin{array}{l}\text { Circuit } \\
\text { element }\end{array}$ & $\begin{array}{l}\text { Inductance } \\
(\mathrm{L}, \mathbf{H})\end{array}$ & $\begin{array}{l}\text { Ohmic } \\
\text { resistance } \\
(\mathrm{Rs}, \boldsymbol{\Omega})\end{array}$ & $\begin{array}{l}\text { Warburg } \\
\text { coefficient } \\
\text { related to } \\
\text { species }\left(\mathrm{W}_{\mathrm{R}} \text {, }\right. \\
\boldsymbol{\Omega})\end{array}$ & $\begin{array}{l}\text { Warburg } \\
\text { coefficient } \\
\text { related to } \\
\text { transport } \\
(\mathrm{Wt}, \mathbf{v})\end{array}$ & $\begin{array}{l}\text { Warburg } \\
\text { constant } \\
\text { phase } \\
\text { (phi) }\end{array}$ & $\begin{array}{l}\text { Double } \\
\text { layer } \\
\text { capacitance } \\
(\mathrm{C}, \mathbf{F})\end{array}$ & $\begin{array}{l}\text { Charge } \\
\text { transfer } \\
\text { resistance } \\
(\text { Rct }, \Omega)\end{array}$ \\
\hline $\begin{array}{l}\text { Fitting value } \\
\text { (error in } \%)\end{array}$ & $10^{-6}(4 \%)$ & $\begin{array}{l}3.715 \\
(0.2 \%)\end{array}$ & $474(4 \%)$ & $1.25(7 \%)$ & 0.53 & $\begin{array}{l}6 \times 10^{-5} \\
\%\end{array}$ & 0.29 (fixed) \\
\hline
\end{tabular}

12

13 
1 List of Figures

2 Figure 1. a. First two cycles of a dc voltammogram at $20 \mathrm{mV} \mathrm{s}^{-1}$ recorded with a static iridium

3 electrode in electrolyte SB4. b. First cycle of a dc voltammogram of a static iridium electrode in 4 different electrolytes.

Figure 2. Impedance spectrum at $\mathrm{OCP}(100 \mathrm{kHz}$ to $0.1 \mathrm{~Hz}, 10 \mathrm{mV}$ excitation) on a static iridium electrode in electrolyte SB4. The closed and open circles are the measured data points, the former having a positive imaginary component. The line through the data is the fit to the equivalent circuit shown inset (details and results in Appendix 2).

Figure 3. Nyquist representation of the MS measurements in electrolyte SB4 for frequencies from $20 \mathrm{kHz}$ to $100 \mathrm{~Hz}$ (truncated at $200 \mathrm{~Hz}$ for potentials higher than $0.951 \mathrm{~V}$ ) for a $10 \mathrm{mV}$ perturbation 13 amplitude with a dc potential scan rate of $15 \mathrm{mV} \mathrm{s}^{-1}$.

Figure 4. Variation of the real part of the impedance with the dc potential for a $20 \mathrm{kHz}$ perturbation (same parameters as in Figure 3).

Figure 5. Variation of the ac amplitude with dc potential (same parameters as in Figure 3) from MS measurements at different perturbation frequencies. The ac amplitude is calculated from Equation 1.

Figure 6. Variation of the peak ac amplitude for $A 1$ and $A 2$ (range 3 ) as a function of the squareroot of the frequency. Open symbols are the experimental data, and the lines are linear trends.

Figure 7. Variation of the direct current with the rotation rate of an iridium rotating electrode in electrolyte SB2F. The scan-rate was $50 \mathrm{mV} \mathrm{s}^{-1}$ (spurious data points due to variations in the contact of the rotating electrode have been removed, amounting to less than $5 \%$ of the points).

Figure 8. Free oxygen concentration data from XPS and Raman spectroscopy (closed symbols, from Refs. [12] and [13]) as a function of optical basicity. The equivalent free oxygen concentration required to observe the current density measured at $2 \mathrm{~V}$ in Figure 2 is presented in the form of open circles. 
1 Fig 1
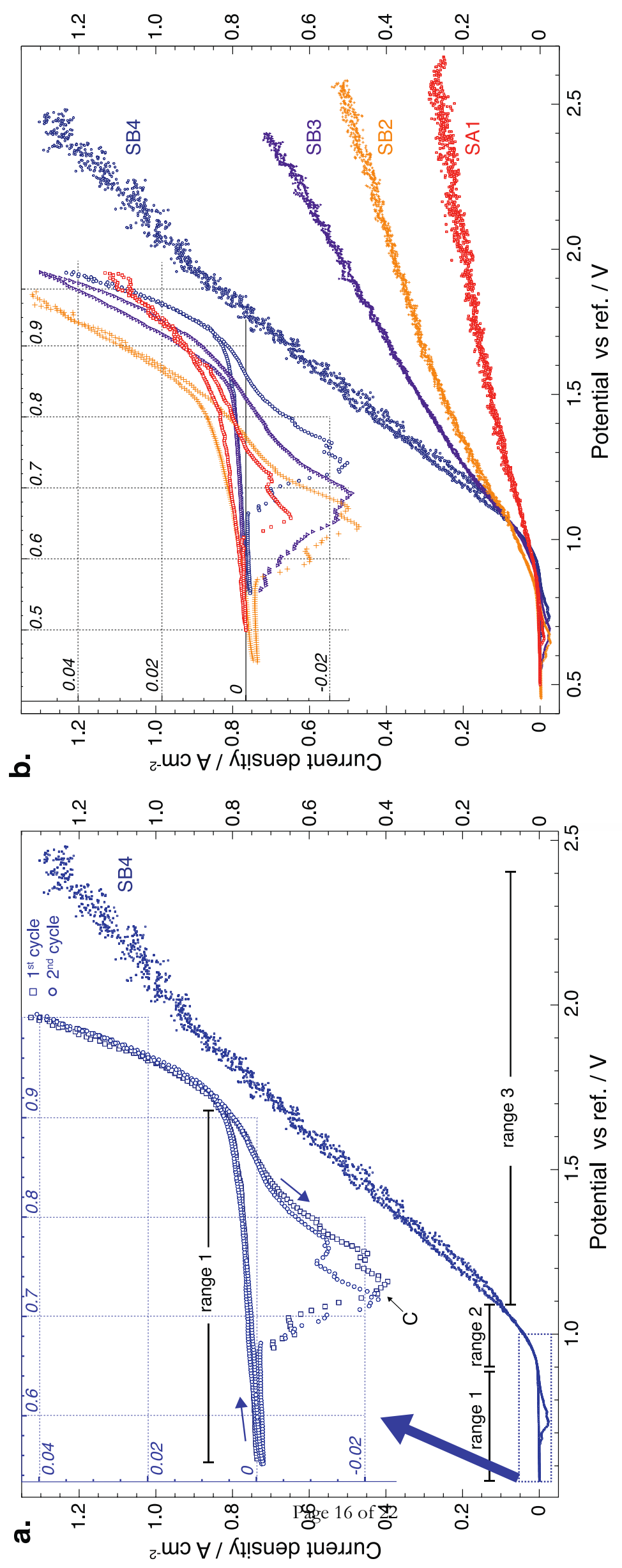
$1 \quad$ Fig 2

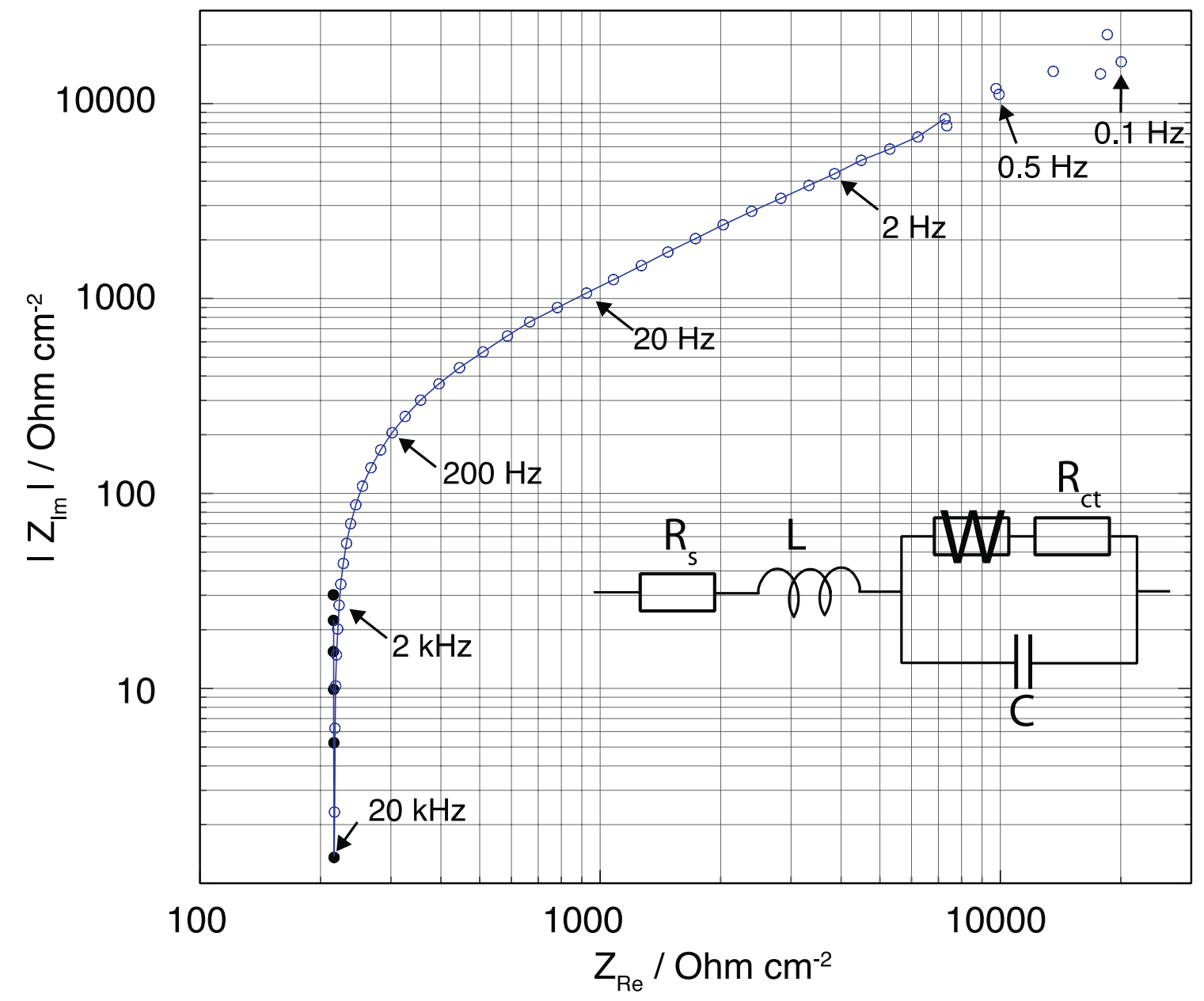

2
3
4
5 
Fig 3

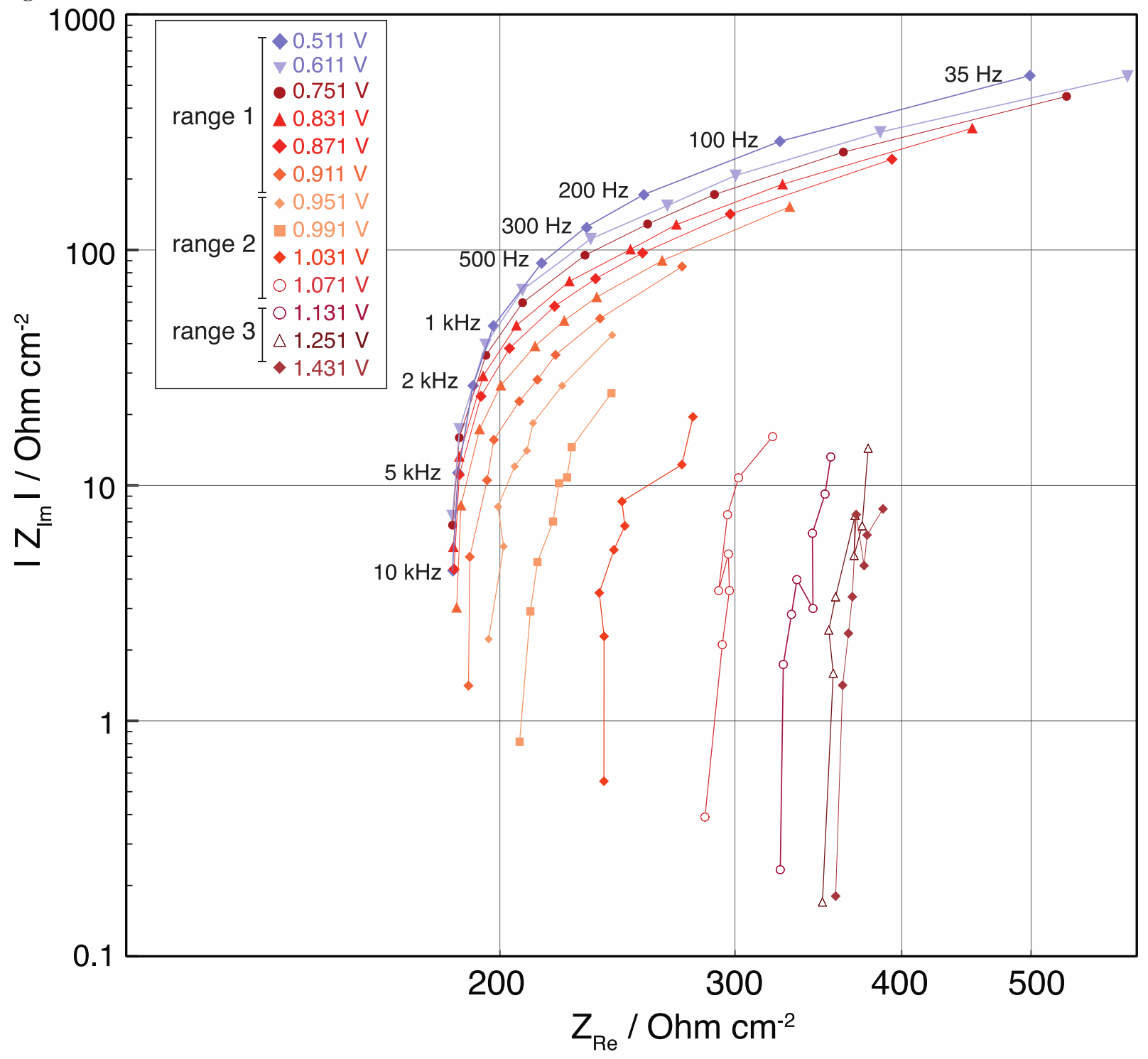

2
3 
$1 \quad$ Fig 4

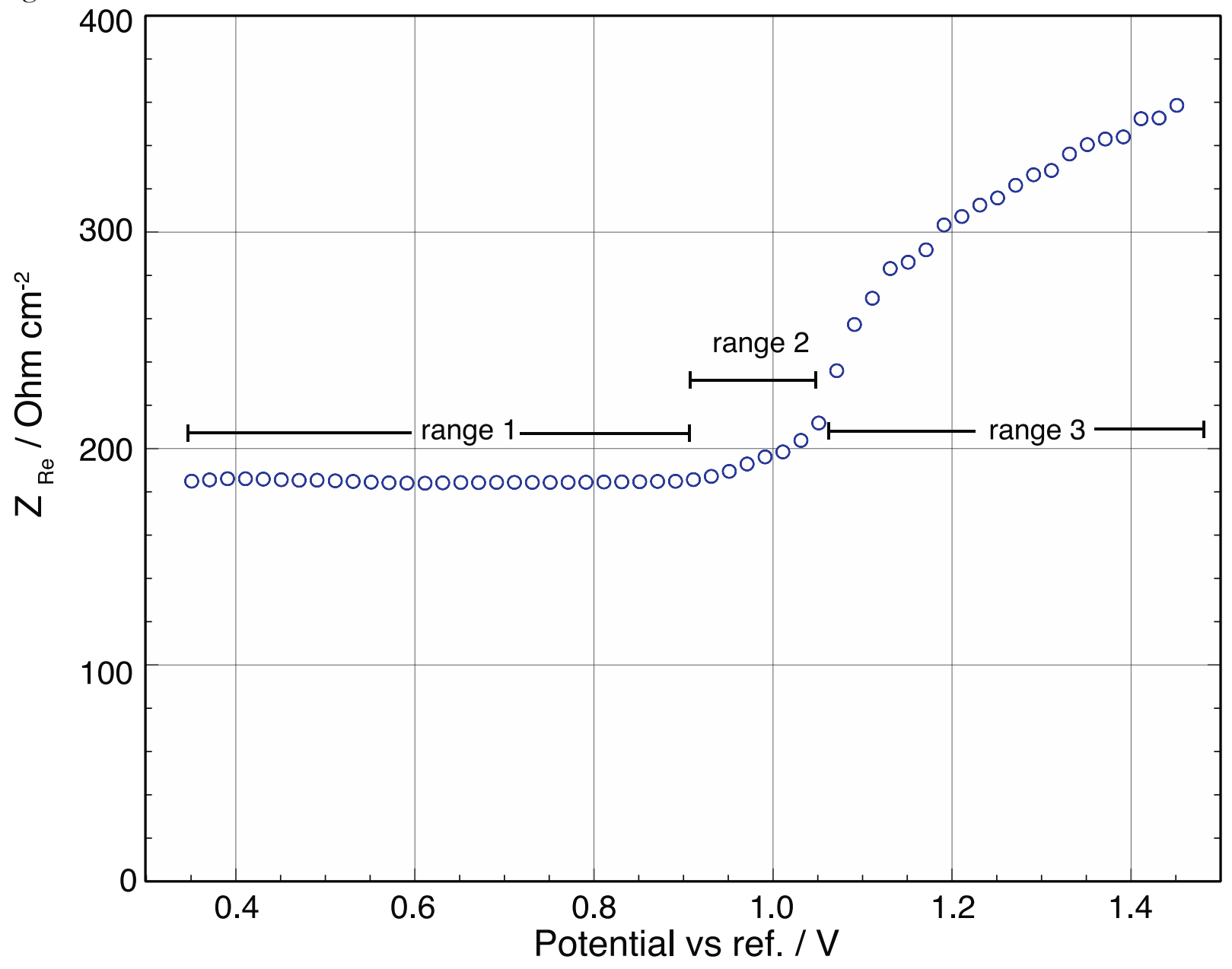

2
3 

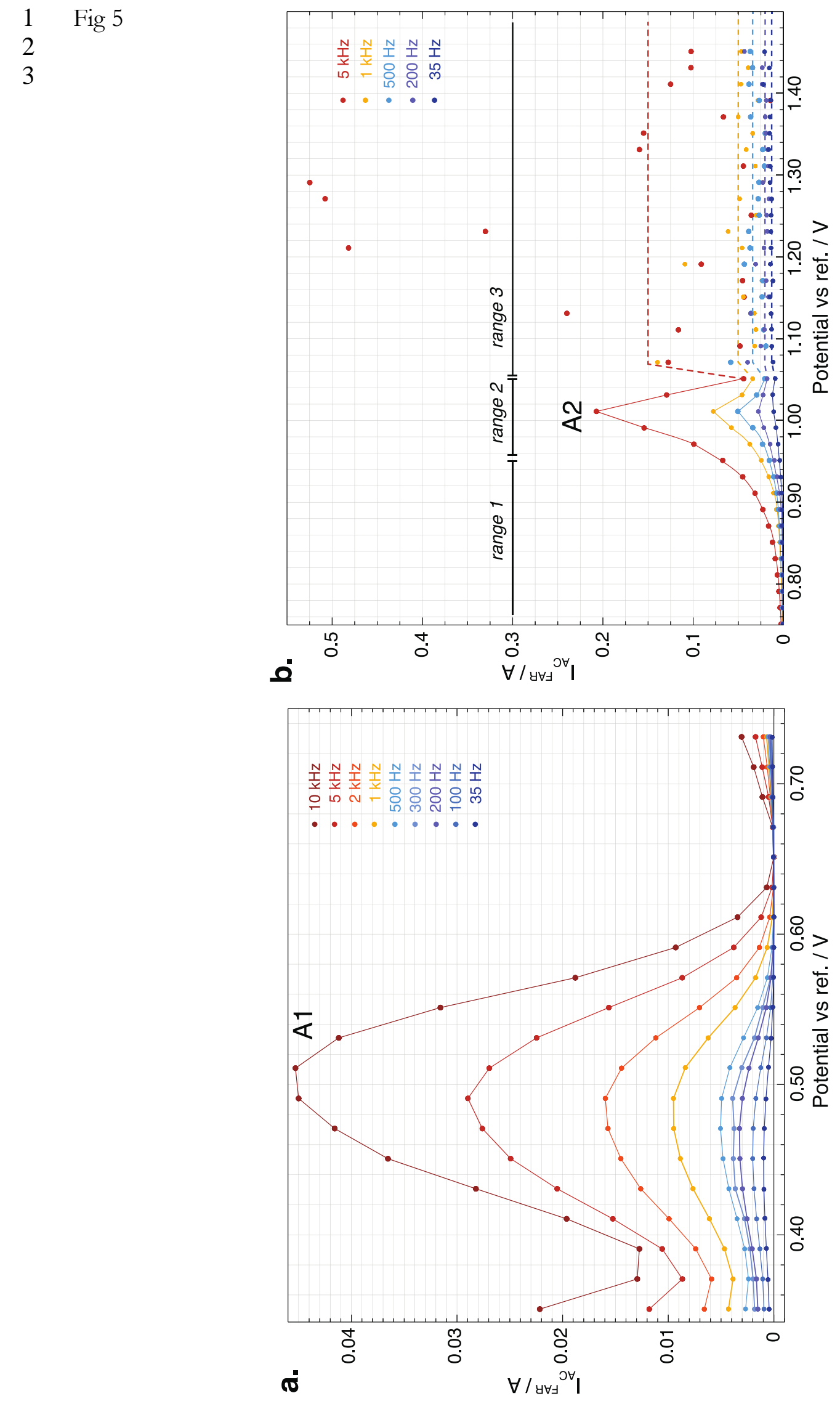

Page 20 of 22 
1 Fig 6

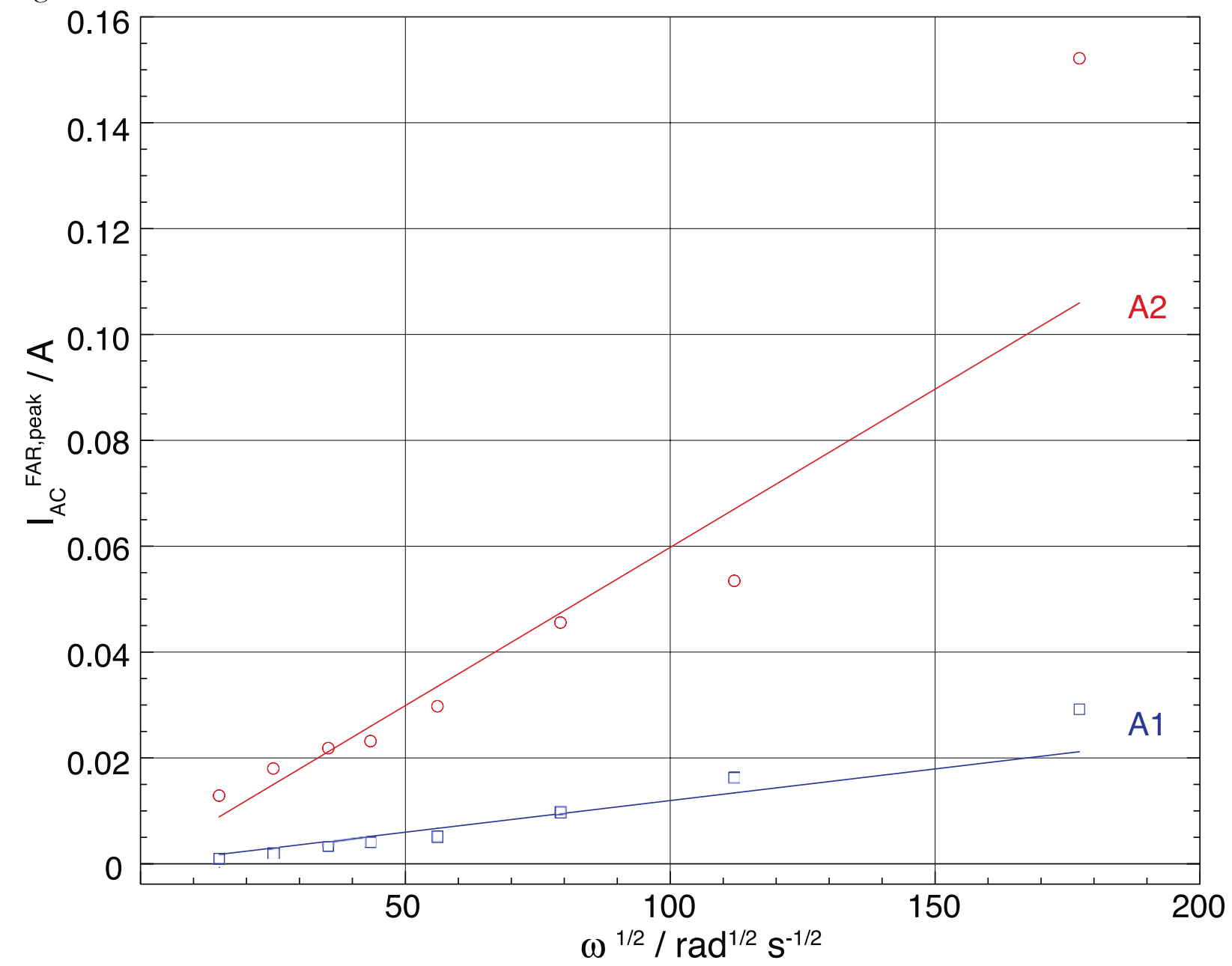

2 
$1 \quad$ Fgi 7

2

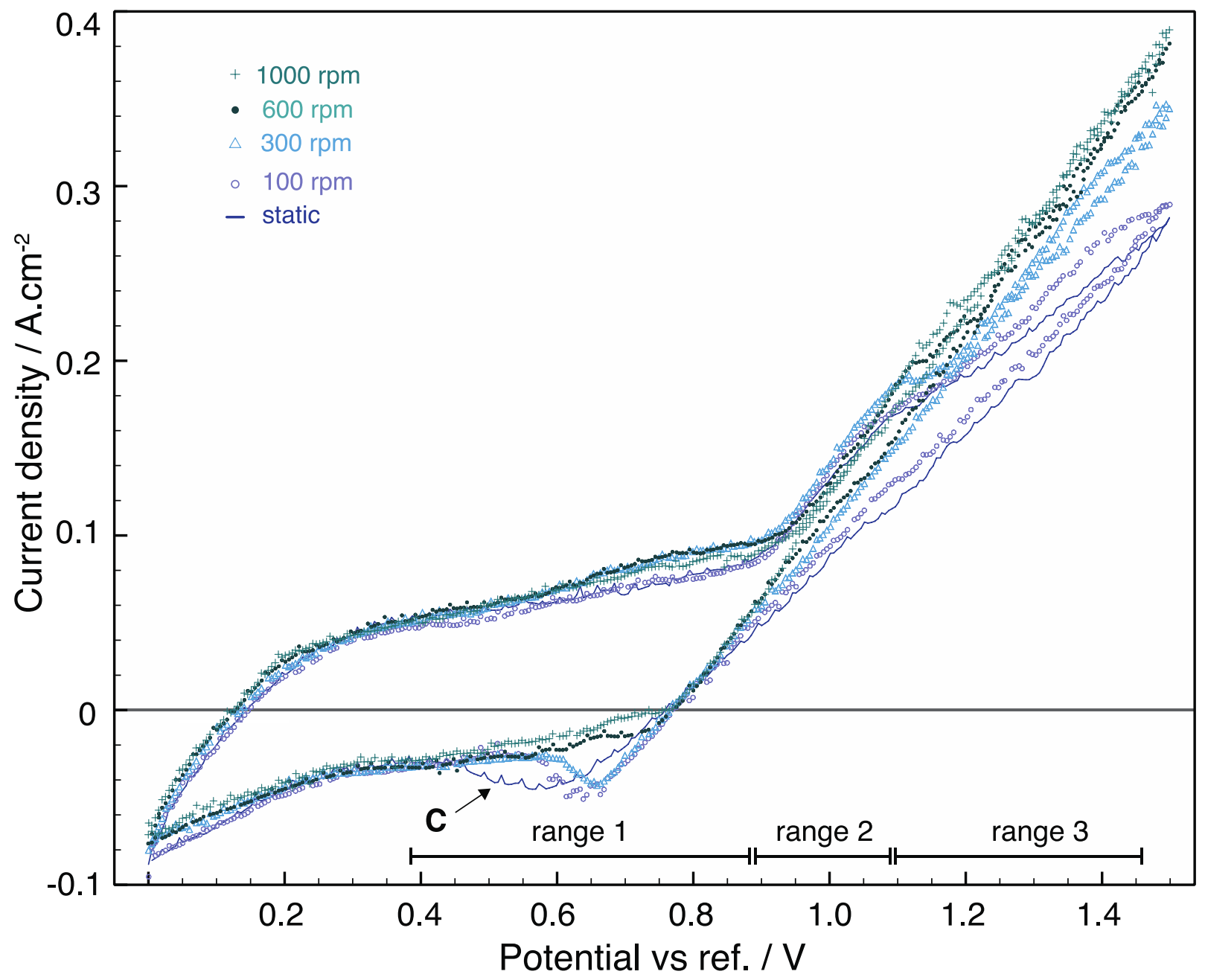

3
4 